\title{
The Effect of Organizational Trust on Employee's Performance through Organizational Commitment as a Mediating Variable (Applied Study on Mobile Phone Companies in Egypt)
}

\author{
Sherin Anwar Abdel Rahman, Mohammed Wahba, Mohamed Abdel Salam Ragheb, \\ Ayman Ahmed Ragab
}

Arab Academy for Science and Technology, Cairo, Egypt

Email: shereenanwardba@gmail.com

How to cite this paper: Rahman, S.A.A., Wahba, M., Ragheb, M.A.S. and Ragab, A.A. (2021) The Effect of Organizational Trust on Employee's Performance through Organizational Commitment as a Mediating Variable (Applied Study on Mobile Phone Companies in Egypt). Open Access Library Journal, 8: e7806.

https://doi.org/10.4236/oalib.1107806

Received: July 29, 2021

Accepted: August 16, 2021

Published: August 19, 2021

Copyright $\odot 2021$ by author(s) and Open Access Library Inc.

This work is licensed under the Creative Commons Attribution International License (CC BY 4.0).

http://creativecommons.org/licenses/by/4.0/

(c) (i) Open Access

\begin{abstract}
The purpose of paper is to explore the role of the organizational commitment as a mediating variable between organizational trust and employee's performance in these organizations, and also the paper aims to review the concept of Organizational Commitment, concept of organizational trust and employee's performance in service business organizations. In order to achieve the purposes of the study, researcher adopted a descriptive analytical method. The researcher distributed 450 questionnaires, and the return was 404 questionnaires, rating $89.77 \%$ of the distributed questionnaires. Analyzing data was conducted using a set of statistical methods including a normality test along with Cronbach's alpha, standard deviation, confirmatory factor analysis, exploratory factor analysis, multiple and simple linear regression using SPSS-V26 and AMOS-V26. The study reached a set of results, the most important of which are: 1 ) There is a statistically impact at significant level ( $\alpha \leq$ 0.05 ) of organizational trust on employee's performance through the Organizational Commitment as a mediating variable in Mobile phone companies in Egypt. 2) There is a significant correlation between Organizational Commitment and organizational trust, and also there is a significant correlation between organizational trust and employee's performance, and finally there is a significant correlation between organizational commitment and employee's performance. The study reached a set of recommendations, the most important of which are: 1) Organizations need high level of interpersonal trust among the co-workers in organization, for successful feedback and observa-
\end{abstract}


tion of advanced organizational behavior. 2) Attention of top management and decision makers of organizations to take measures to enhance employees' performance through increased commitment level, whereas improved employee performance result is the aim for every organization.

\section{Subject Areas}

Organizational Behavior and Theory

\section{Keywords}

Organizational Commitment, Organizational Trust, Employee's Performance

\section{Introduction}

Organizations existence, survival and continuity depends on achieving their goals, and achieving goals is linked to individuals who have high confidence in their organization, its managers and co-workers, as trust in work relationships is one of the mainstays that help organizations to strengthen their effectiveness and achieve their goals, and it is one of the most effective administrative tools, because it prepares the conditions necessary for the success of organizations [1].

One of the most critical issues facing all organizations today is how to improve organizational trust at work. It is becoming increasingly recognized that trust in the workplace is a critical factor leading to increasing performance in organizations [2].

Organizational trust is one of the powerful forces in building the personality of the organization, as it encourages organizational stability and satisfaction among members of the organization, helps reduce negative conflicts and enhances effective responses in solving problems [3]. Organizational trust has many positive effects for both organizations and the employees. In organizations where organizational trust is ensured, employees have high morale and loyalty, which reflects good behaviour towards the organization, colleagues and managers [4].

There is a big link between organizational trust and organizational commitment. It's considered as the most important entraining factors for organizational success. The most important factor in the formation of organizational commitment is trust that employees have in their organizations [5]. The organizational commitment is considered to be a linking or bond between organizations and individual [6]. Organizational commitment is the relative strength of an individual's identification with and involvement in organization [7]. And high levels of commitment may cause valuable organizational outcomes. Commitment is associated with reducing absenteeism, turnover and counterproductive behavior, and organizational commitment is positively associated with job satisfaction, motivation and organizational citizenship behavior [8]. 
The performance of employees is considered as a very important issue due to the increase concern of organizational experts and human resources about the level of output obtained from workers [9]. Job performance can be defined as the overall expected value from employees' behaviors carried out over the course of a set period of time [10]. Organizational trust and organizational commitment have importance in keeping the performance in organizations at high level and in getting desired results in terms of organizations [11]. Accordingly, this study seeks to test the impact of organizational trust on the employee's performance of Mobile phone companies employees, through Organizational Commitment as a mediating variable.

\section{Research Design}

\subsection{Objectives of the Research}

The objectives of the research are:

1) Determining the level of organizational trust according to its dimensions (trust in supervisors, trust in coworker, trust in upper-management, trust in organizational Climate) among the research sample in mobile phone service companies in Egypt.

2) Reviewing the concept of Organizational Commitment, identifying Organizational Commitment dimensions, and concepts of job and employee's performance.

3) Identify the ways in which organizational trust process can be relevant to attain the goals of Organizational Commitment.

4) Exploring the role of the Organizational Commitment as a mediating variable between organizational trust and employee's performance in service or business organizations in general, and the Mobile phone companies in Egypt in particular.

5) Reaching out to a set of recommendations that, if implemented, are expected to lead to the improvement and development of organizations employee's performance.

\subsection{Research Questions}

Is there a statistical relationship with a significant impact between organizational trust and the employee's performance of this type of service organization?

Do human resource management policies affect the Organizational Commitment of Mobile phone companies?

Does the Organizational Commitment affect the employee's performance of Mobile phone companies employees?

Is there an impact of organizational trust on employee's performance through the Organizational Commitment as a mediating variable?

\subsection{Research Model}

Figure 1 shows the research model of this study. 


\subsection{Research Hypothesis}

In order to trying to answer the research questions, According to literature review and previous studies,

The following hypotheses were developed to decide if there is a significant impact organizational trust on Organizational Commitment:

- There is a statistically significant effect of organizational trust on Organizational Commitment.

- There is a statistically significant effect of organizational trust on employee's performance.

- There is a statistically significant effect of the organizational commitment on employee's performance.

- There is a statistically significant effect of organizational trust on employee's performance through the organizational commitment as a mediator variable.

To verify previous hypotheses, regression and correlation has been conducted using statistical techniques and programs.

\section{Research Methodology}

The study adopted a descriptive analytical method, the questionnaire was study's main tool for collecting data; where (450) questionnaires were distributed, and (404) questionnaires were retrieved for analysis, the rate was (89.7\%) of the distributed questionnaires. Analyzing data was conducted using a set of statistical methods including Cronbach's alpha, means, standard deviation, confirmatory factor analysis, exploratory factor analysis, multiple and simple linear regression using SPSS-V26 and AMOS-V26.

\subsection{Study Tool}

The study of data collected through questionnaires has four sources: basic respondent demographic data, organizational trust, Organizational Commitment, and employee's performance.

The 35-item scale of organizational trust section is based on (Khwein, 2015) [12]. There were 8 items measuring trust in supervisors, 10 items measuring,

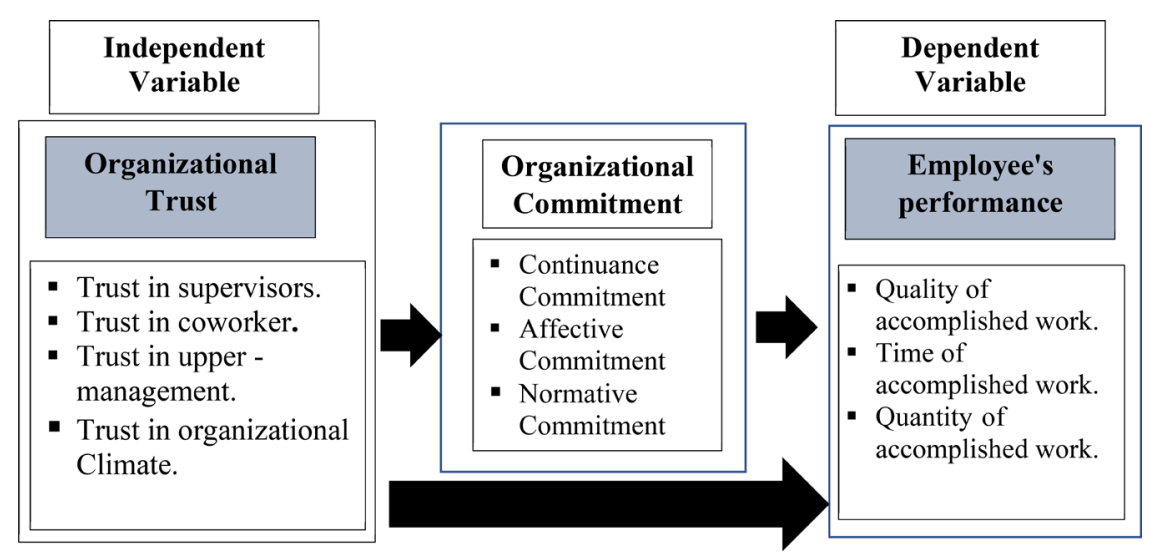

Figure 1. Research model of this study. 
trust in coworker, 10 items measuring, trust in upper -management, and 7 items measuring, trust in organizational Climate.

The 22-item scale of Organizational Commitment section is based on (Kazem, 2010) [13]. There were 7 items measuring continuance commitment, 7 items measuring affective commitment, and 8 items measuring normative commitment

The 18-item scale of employee's performance section is based on (Abu juladaydah, 2018) [14]. There were 6 items measuring continuance commitment, 6 items measuring affective commitment, and 6 items measuring normative commitment.

Responses to all items scales were anchored on a five (5) point Likert scale for each statement which ranges from (5) "full agreement", (4) for "agree", (3) for "neutral", (2) for “disagree", and (1) for "full disagreement".

\subsection{Questionnaire Design}

\subsubsection{Questionnaire Design Principal}

Study questionnaire to be in the final form as shown, researcher had the following steps:

- Review the literature and previous studies related to the subject of the study, to have the structure in building the questionnaire and formulating its paragraphs.

- The researcher consulted a number of Egyptian university professors and administrative supervisors in the field.

- Determining the main dimensions of the questionnaire according to the study variables.

- Determine the main items for each dimension included in the questionnaire.

- Determine items that fall under each dimension.

- Presenting the questionnaire to the supervisor for discussion and comments.

- The questionnaire was designed in its initial form and it consisted of three main dimensions and (75) items.

- The questionnaire was judged by (5) arbitrators with experience in academic and professional field.

- According to arbitrators' opinions, some items of the questionnaire were modified in terms of deletion, addition and modification.

- In order for the questionnaire to settle in its final form on (75) items.

\subsubsection{Questionnaire Items}

A questionnaire was prepared on "the impact of the Organizational Commitment as a mediating variable between organizational trust and employee's performance" applied study Mobile phone companies in Egypt.

The questionnaire consists of:

1) Part 1: personal data.

2) Part Two: variables dimensions and items.

Table 1 shows the sources of the questionnaire items and number of items, 
that were developed from previous studies:

Description of the demographic characteristics of the study sample:

The demographic characteristics of the study sample members were analyzed in terms of (gender, age, marital status, academic qualification, practical experience in the current job, administrative level) and the results were as follows:

Gender:

Table 2 shows the numbers and percentages of the sample members in terms of gender.

The number of males (148) from all study sample numbers (64\%), while the number of females is (142), (36\%).

Age:

Table 3 shows the numbers and percentages of the sample members in terms of the age groups.

The number of individuals in the age group (Over 25 and under 35 years old) is the largest segment of the study sample, a total number of (145) individuals, at a rate of (\%35.89) while the age group segment (Under 25 years old), the lowest age group, with a total number of (34) members of the study sample, at a rate of (8.42\%).

Table 1. Questionnaire items.

\begin{tabular}{cccc}
\hline Variable & No of & Item \\
Item & Range & Source \\
Independent Variable: Organizational trust & 35 & & \\
Trust in supervisors & 8 & $1-8$ & (Khwein, 2015) \\
Trust in coworker & 10 & $9-18$ & \\
Trust in upper-management & 10 & $19-28$ & \\
Trust in organizational Climate & 7 & $29-35$ & (Kazem, 2010) \\
Mediating Variable: Organizational Commitment & 22 & & \\
Continuance commitment & 7 & $36-42$ \\
Affective commitment & 7 & $43-49$ \\
Normative commitment & 8 & $50-57$ & \\
Quantity of accomplished work & 18 & & \\
Time of accomplished work & 6 & $58-63$ \\
Dependent Variable: Employee's performance & $64-69$ &
\end{tabular}

Table 2. Gender.

\begin{tabular}{ccc}
\hline Item & No & Per \\
\hline Male & 146 & $36.14 \%$ \\
Female & 258 & $63.86 \%$ \\
& 404 & $100 \%$ \\
\hline
\end{tabular}




\section{Job Category}

Table 4 shows the numbers and percentages of the sample members in terms of the Job Category groups.

The number of individuals in the age group (Executive Management) is the largest segment of the study sample, a total number of (288) individuals, at a rate of (71.29\%) while the age group segment (Strategic management), the lowest age group, with a total number of (95) members of the study sample, at a rate of (23.51\%).

\section{Number of years of experience in the company:}

Table 5 shows the numbers and percentages of sample members in terms of number of years of work and experience in the company.

The number of individuals in the years of work and experience group (Over 15 and less than 25 years) is the largest segment of the study sample, a total number of (174) individuals, at a rate of (43.07\%) while the age group segment (Less than 5 Years), the lowest experience group, with a total number of (24) members of the study sample, at a rate of (5.94\%).

Table 3. Age groups.

\begin{tabular}{ccc}
\hline Item & No & Per \\
\hline Under 25 years old & 34 & $8.42 \%$ \\
Over 25 and under 35 years old & 145 & $35.89 \%$ \\
Over 35 and less than 45 years old & 114 & $28.22 \%$ \\
Over 45 and less than 55 years old & 67 & $16.58 \%$ \\
Over 55 years old & 44 & $10.89 \%$ \\
& 404 & $100 \%$ \\
\hline
\end{tabular}

Table 4. Job Category groups.

\begin{tabular}{ccc}
\hline Item & No & Per \\
\hline Executive Management & 288 & $71.29 \%$ \\
Middle management & 95 & $23.51 \%$ \\
Strategic management & 21 & $5.20 \%$ \\
& 404 & $100 \%$ \\
\hline
\end{tabular}

Table 5. Number of years of experience in the company.

\begin{tabular}{ccc} 
Item & No & Per \\
\hline Less than 5 years & 24 & $5.94 \%$ \\
Over 5 and less than 15 years & 142 & $35.15 \%$ \\
Over 15 and less than 25 years & 174 & $43.07 \%$ \\
More than 25 years & 64 & $15.84 \%$ \\
& 404 & $100 \%$ \\
\hline
\end{tabular}




\subsection{Pilot Study}

Before administering questionnaires, it was necessary to first evaluate the reliability and validity of the instruments. Therefore, this research used Cronbach Coefficient alpha to statistically check the items reliability. And to evaluating the validity of a measurement instrument evaluated content validity, criterion-related validity, and construct validity.

In order to testing questionnaire validity and reliability, the researcher distributed sample of (35) questionnaires.

\subsubsection{Evaluating Reliability}

The reliability of the study questionnaire was verified by Cronbach's Alpha coefficient, and the results showed the Cronbach Alpha coefficient (99.7\%) which is a statistically acceptable level as long as it is greater than (0.6).

\subsubsection{Evaluating Validity}

In this research, all scales for measuring study variables constructs have content validity since the development of these measurement items was based mainly on an extensive review of the literature, all questionnaire items judged by arbitrators with experience in academic and professional field.

Table 6. Reliability of questionnaire.

\begin{tabular}{|c|c|c|c|}
\hline Dimensions & No of Items & Items & Cronbach Alpha coefficient \\
\hline \multicolumn{4}{|c|}{ independent Variable: Organizational Trust } \\
\hline Trust in supervisors & 8 & $1-8$ & 0.969 \\
\hline Trust in coworker & 10 & $9-18$ & 0.97 \\
\hline Trust in upper -management & 10 & $19-28$ & 0.973 \\
\hline Trust in organizational Climate & 7 & $29-35$ & 0.964 \\
\hline \multicolumn{3}{|c|}{ Independent Variable Cronbach Alpha coefficient } & 0.984 \\
\hline \multicolumn{4}{|c|}{ Mediating Variable: Organizational Commitment } \\
\hline Continuance commitment & 7 & $36-42$ & 0.951 \\
\hline Affective commitment & 7 & $43-49$ & 0.947 \\
\hline Normative commitment & 8 & $50-57$ & 0.961 \\
\hline \multicolumn{3}{|c|}{ Mediating Variable Cronbach Alpha coefficient } & 0.974 \\
\hline Dependent Variable: & \multicolumn{3}{|c|}{ Employee's performance } \\
\hline Quality of accomplished work & 6 & $58-63$ & 0.958 \\
\hline Time of accomplished work & 6 & $64-69$ & 0.926 \\
\hline Quantity of accomplished work & 6 & $70-75$ & 0.949 \\
\hline \multicolumn{3}{|c|}{ Depending Variable Cronbach Alpha coefficient } & 0.965 \\
\hline \multicolumn{3}{|c|}{ Total Cronbach Alpha coefficient } & 0.997 \\
\hline
\end{tabular}




\section{Results}

\subsection{First Main Hypothesis Test}

To test the first main hypothesis, the null hypothesis was developed which is that there is no significant statistical effect of organizational trust of Mobile phone companies on the organizational commitment, and to verify the validity of the hypothesis, the simple regression test was used between organizational trust as an independent variable, and the organizational commitment is a dependent variable, Table 5 shows the results as follows:

It is evident from Table 7 that the statistical value (T) is (91.81) with a statistical significance level less than $5 \%(\mathrm{p} \leq 0.05)$, we reject the null hypothesis, which indicates that there is a statistically significant impact of organizational trust on the Organizational Commitment, and accordingly we conclude that there is a statistically significance of organizational trust on the Organizational Commitment.

$$
\text { Regression equation is: } \mathrm{y}=\propto+\mathrm{B} x
$$

Organizational Commitment $=0.071+1.023$ organizational trust.

\subsection{Sub-Hypotheses Test for the First Main Hypothesis}

To test the sub-hypotheses, the null hypothesis was developed that is represented by the absence of a statistically significant impact from the dimensions of organizational trust (knowledge acquisition, knowledge storage, Knowledge sharing, knowledge utilization) on the Organizational Commitment, and to verify the validity of the hypothesis, the multiple regression test was used between the dimensions of organizational trust (knowledge acquisition, knowledge storage, knowledge sharing, knowledge utilization) as independent variables and Organizational Commitment as a dependent variable, Table 8 shows the results as follows:

Table 7. Simple regression Analysis results for organizational trust and organizational commitment.

\begin{tabular}{cccc}
\hline & B & T & Sig \\
\hline Constant & 0.071 & 1.59 & 0.112 \\
organizational trust & 1.023 & 91.81 & 0.000 \\
\hline
\end{tabular}

Table 8. Multiple regression Analysis results for organizational trust dimensions and Organizational Commitment.

\begin{tabular}{ccccc}
\hline Organizational trust Dimensions & B & Beta & T & Sig \\
\hline Constant & 0.019 & & 0.430 & 0.667 \\
Trust in supervisors & 0.716 & 0.699 & 6.573 & 0.000 \\
Trust in coworker & 0.348 & 0.338 & 2.521 & 0.012 \\
Trust in upper -management & 0.046 & 0.044 & 0.530 & 0.596 \\
Trust in organizational Climate & 0.111 & 0.104 & 2.227 & 0.027 \\
\hline
\end{tabular}


According to Table 8, it becomes clear that the statistical value (T) of the dimensions of organizational trust (trust in supervisors, trust in coworker, trust in upper -management, trust in organizational Climate) amounted to $(6.57,2.51$, $0.53,2.22)$, respectively, with a level of statistical significance less than $5 \%$. Amounted to $(0.000,0.012,0.596,0.027)$. It is evident that there is a statistically significant effect from three dimensions of organizational trust (trust in supervisors, trust in coworker, trust in organizational Climate) on the Organizational Commitment as all values of the significance level coefficients (Sig) are less than 0.05 , but the fourth dimension (trust in upper -management,) is not significant (more than 5\%) which indicates the presence of a insignificant effect.

$$
\text { Regression equation is: } \mathrm{y}=\propto+\mathrm{B} x
$$

$$
\text { Organizational Commitment }=0.019+0.716 X_{1}+0.348 X_{2}+0.046 X_{3}+111 X_{4}
$$

where,

$$
\begin{aligned}
& X_{1}=\text { trust in supervisors } \\
& X_{2}=\text { trust in coworker } \\
& X_{3}=\text { trust in upper -management } \\
& X_{4}=\text { trust in organizational Climate }
\end{aligned}
$$

\subsection{Second Main Hypothesis Test}

To test the second main hypothesis, the null hypothesis was developed which is that there is no significant statistical effect of organizational trust on the employee's performance of Mobile phone companies.

Table 9 shows the results as follows:

$$
\text { Regression equation is: } \mathrm{y}=\propto+\mathrm{B} X
$$

employee's performance $=0.039+0.997$ organizational trust.

It is evident from Table 9 that the statistical value (T) is (115.22) with a statistical significance level less than $5 \%$, which indicates that there is a statistically significance impact of organizational trust on employee's performance.

\subsection{Sub-Hypotheses Test for the Second Main Hypothesis}

To test the sub-hypotheses, the null hypothesis was developed that is represented by the absence of a statistically significant impact from the dimensions of organizational trust (trust in supervisors, trust in coworker, trust in upper -management, trust in organizational Climate) on the Organizational Commitment, and to verify the validity of the hypothesis, the multiple regression test was used between the dimensions of organizational trust (trust in supervisors,

Table 9. Simple regression Analysis results for organizational trust and employee's performance.

\begin{tabular}{cccc}
\hline & B & T & Sig \\
\hline Constant & 0.039 & 1.13 & 0.258 \\
organizational trust & 0.997 & 115.22 & 0.000
\end{tabular}


trust in coworker, trust in upper -management, trust in organizational Climate) as independent variables and employee's performance as a dependent variable, Table 10 shows the results as follows:

According to Table 10 it becomes clear that the statistical value $(\mathrm{T})$ of the dimensions of organizational trust (trust in supervisors, trust in coworker, trust in upper -management, trust in organizational Climate) amounted to $(2.38,2.42$, $13.01,1.24)$, respectively, with a level of statistical significance less than $5 \%$. Amounted to $(0.000,0.000,0.002,0.260)$ It is evident that there is a statistically significant effect two dimensions of organizational trust (trust in supervisors, trust in coworker, trust in upper -management) on employee's performance as all values of the significance level coefficients (Sig) are less than 0.05 , but the fourth dimension (trust in organizational Climate) is not significant (more than $5 \%$ ) which indicates the presence of a insignificant effect.

$$
\text { Regression equation is: } \mathrm{y}=\propto+\mathrm{B} X
$$

employee's performance $=0.093+0.354 X_{1}+0.791 X_{2}+0.204 X_{3}+0.043 X_{4}$ where,

$$
\begin{aligned}
& X_{1}=\text { trust in supervisors } \\
& X_{2}=\text { trust in coworker } \\
& X_{3}=\text { trust in upper -management } \\
& X_{4}=\text { trust in organizational Climate }
\end{aligned}
$$

\subsection{Third Main Hypothesis}

To test the third main hypothesis, the null hypothesis was developed, which is the absence of a statistically significant relationship between organizational trust and employee's performance through the organizational commitment as a mediating variable.

And to verify the validity of the hypothesis and study the extent of a complete or partial relationship, the Path Analysis test was used, using the Amos 26 program.

The model consists of the following variables:

1) Observed Exogenous Variables: The independent variable includes organizational trust.

2) Observed Endogenous Variables: The dependent variable includes employee's

Table 10. Multiple regression Analysis results for organizational trust dimensions and employee's performance.

\begin{tabular}{ccccc}
\hline organizational trust Dimensions & B & Beta & T & Sig \\
\hline Constant & 0.093 & & 3.716 & 0.007 \\
Trust in supervisors. & 0.354 & 0.357 & 2.388 & 0.000 \\
Trust in coworker & 0.791 & 0.793 & 2.426 & 0.000 \\
$\quad \begin{array}{c}\text { Trust in upper-management } \\
\text { Trust in organizational Climate }\end{array}$ & 0.204 & 0.205 & 13.011 & 0.002 \\
\hline
\end{tabular}


performance, and the mediating variable includes the Organizational Commitment.

3) Unobserved Exogenous Variables: Measurement errors of the dimensions of the dependent variable include employee's performance, and the mediating variable, Organizational Commitment.

Figure 2 and Table 11 illustrate the mediating effect (direct and indirect) of organizational commitment between organizational trust and employee's performance.

From the previous table and figure, it is clear that at a level of significance 0.05 , there is a statistically significant effect of organizational trust path on the Organizational Commitment with a factor of $0.997 \approx 1$, and the Organizational Commitment Path on employee's performance with an impact factor of 0.96 , as the value of the level of significance for both path are 0.000 , which is less than 0.05 .

While there is no statistically significant impact of the organizational trust path on employee's performance, as the value of the level of significance is equivalent to 0.176 (greater than 0.05 .).

For model fit purpose, Table 12 illustrates the model fit indices:

Table 12 shows the following:

Chi-square (X2): tests the null hypothesis of this test is, the model fits the model is better when it has a small value, whereas this model value is 0.000 , model is fit.

Goodness of Fit Index (GFI): purpose of computing GFI in the case of maximum likelihood estimation, GFI is less than or equal to 1 . Whereas model (GFI)

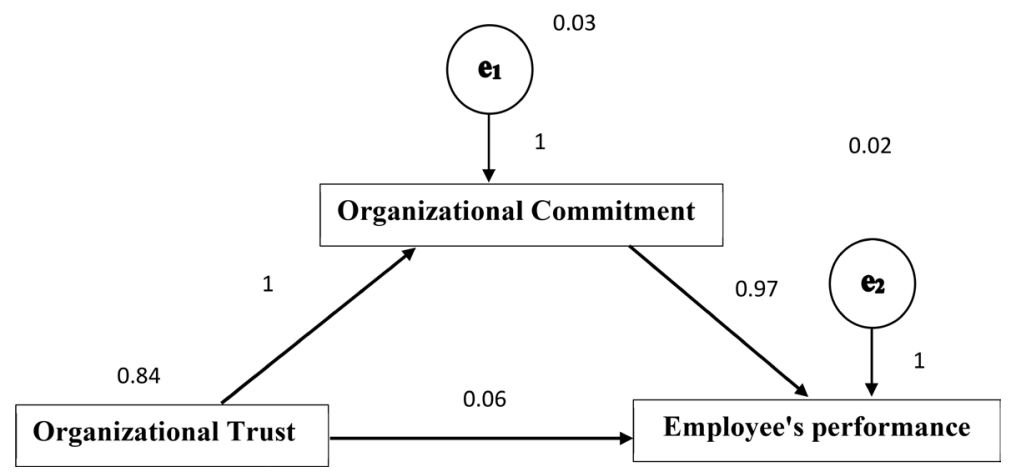

Figure 2. Mediator path.

Table 11. Variables path estimates.

\begin{tabular}{cccccccc}
\hline & Path & Estimate & S.E & C.R & P-value & Sig \\
\hline $\begin{array}{c}\text { Organizational } \\
\text { trust }\end{array}$ & $\rightarrow$ & $\begin{array}{c}\text { Organizational } \\
\text { Commitment }\end{array}$ & 0.997 & 0.009 & 115.364 & 0.000 & Sig \\
$\begin{array}{c}\text { Organizational } \\
\text { Commitment }\end{array}$ & $\rightarrow$ & $\begin{array}{c}\text { Employee's } \\
\text { performance }\end{array}$ & 0.968 & 0.042 & 22.933 & 0.000 & Sig \\
$\begin{array}{c}\text { Organizational } \\
\text { trust }\end{array}$ & $\rightarrow$ & $\begin{array}{c}\text { Employee's } \\
\text { performance }\end{array}$ & 0.058 & 0.043 & 1.354 & 0.176 & In Sig \\
\hline
\end{tabular}


Table 12. Model fit summary.

\begin{tabular}{cc}
\hline Item & Index \\
\hline Chi Square & 0 \\
The Comparative Fit Index (CFI) & 1 \\
Goodness of Fit Index (GFI) & 1 \\
Root Mean Square Residual (RMR) & 0.000 \\
Root Mean Square Error of Approximation (RMSE) & 1.575 \\
\hline
\end{tabular}

amounted 1 , it indicates a perfect fit.

The Comparative Fit Index (CFI): parameter estimate for the model being evaluated; CFI is truncated to fall in the range from 0 to 1 . CFI values close to 1 indicate a very good fit. Whereas this model value is 1 , model is fit.

The square root of the mean squares of remainder (RMR): It is an indicator of the estimated amount, and the model is better when it has a small value, whereas this model value is 1 , model is fit.

Root Mean Square Error of Approximation (RMSEA): Independent model value is 1.575 , the value of the RMSEA of about 0.05 or less would indicate a close fit of the model in relation to the degrees of freedom, but for the independent model, it accepted according to Independent model.

Based on the previous results and after checking the model test and all the criteria for judging model goodness, and accordingly, the relationship to the mediating variable, which is the Organizational Commitment, is a holistic relationship and not a partial one, as there is no significance for the relationship between organizational trust on the employee's performance of the existence of the organizational commitment, which means that the organizational commitment is a necessary condition for the impact of organizational trust on employee's performance.

\section{Recommendations}

- Organizations must build an organizational culture based on teamwork, and self-censorship for workers through instill confidence among individuals working within the business organizations.

- Organizations should organizing training courses in the field of human relations to improve relations between superiors and subordinates to build trust and good relationship among employees and top managers.

- For creating healthy environment of trust, it's necessary for managers to configure the feeling of trust in all employees of the organization and to direct them very carefully.

- The need to pay attention to strengthening the relationship between the organization's administration and staff development and improvement through the intensification of meetings, briefings and open the way for employees to express their views and ideas and discussed objectively and transparently. 
- Managers and leaders are responsible for create the process of organizational trust.

- Organizations need high level of interpersonal trust among the co-workers in organization, for successful feedback and observation of advanced organizational behavior.

- Attention should be given to assets and cognitive development efforts strategically human dimension.

- Attention of top management and decision makers of organizations to take measures to enhance employees' performance through increased commitment level, Whereas Improved employee performance results is aim for every organization.

\section{Conclusion}

This study aimed to explore the role of the organizational commitment as a mediating variable between organizational trust and employee's performance in these organizations. The study result is that there is a statistical impact of organizational trust on employee's performance through the organizational commitment as a mediating variable in mobile phone companies in Egypt. Accordingly, organizational trust plays a very important role in the commitment of their employees, and their intention to stay and continue to work the job. The effectiveness, success, and efficiency of organizations depend on the trust of employees with each other in organizations. Lack of trust feeling, on the other hand, tarnishes the relations in the work environment. It is not possible for people who are acting with suspicion towards each other to reveal a successful work at the end. Organizational commitment is the strongest motivator that highly affects person's intentions to perform well, increases his efficiency, and improves his skills. Organizational commitment is important for organizations, because it is a good predictor of organizational goals and objectives, productivity, absenteeism and turnover.

\section{Conflicts of Interest}

The authors declare no conflicts of interest.

\section{References}

[1] Reçica, L.F. and Doğan, A. (2019) The Relationship between Job Satisfaction, Organizational Trust and Intention to Leave the Job: A Comparative Study between Kosovo and Turkey. Oeconomica, 15, 173-189.

[2] Judeh, M. (2016) The Influence of Organizational Trust on Job Performance: Mediating Role of Employee Engagement. International Journal of Business Research, 16, 53-66. https://doi.org/10.18374/IJBR-16-5.4

[3] Olander, H., Vanhala, M. and Hurmelinna-Laukkanen, P. (2016) Preserving Prerequisites for Innovation: Employee-Related Knowledge Protection and Organizational Trust. Baltic Journal of Management, 11, 493-515.

https://doi.org/10.1108/BJM-03-2015-0080 
[4] Güçer, E. and Demirdağ, Ş.A. (2014) Organizational Trust and Job Satisfaction: A Study on Hotels. Business Management Dynamics, 4, No. 1.

[5] Baştug, G., Pala, A., Kumartaşli, M., Günel, I. and Duyan, M. (2016) Investigation of the Relationship between Organizational Trust and Organizational Commitment. Universal Journal of Educational Research, 4, 1418-1425. https://doi.org/10.13189/ujer.2016.040619

[6] Rahayuningsih, I. (2019) The Positive Impact of Organizational Trust: a Systematic Review. Journal of Educational, Health and Community Psychology, 8, 122-143. https://doi.org/10.12928/jehcp.v8i1.12195

[7] Rukshani, K. and Senthilnathan, S. (2014) Impact of Organizational Trust on Employee Morale. ELK Asia Pacific Journal of Human Resource Management and Organisational Behaviour, 1, 1-25. https://doi.org/10.2139/ssrn.2430035

[8] Suharto, S. and Hendri, N. (2019) The Impact of Organizational Commitment on Job Performance. International Journal of Economics and Business Administration, 7, 189-206.

[9] Hemakumara, M.G.G. (2020) The Impact of Motivation on Job Performance: A Review of Literature. Journal of Human Resources Management and Labor Studies, 8, 24-29.

[10] Khan, M.R., Ziauddin, Z., Jam, F.A. and Ramay, M.I. (2010) The Impacts of Organizational Commitment on Employee Job Performance. European Journal of Social Sciences, 15, 292-298.

[11] Tella, A., Ayeni, C.O. and Popoola, S.O. (2007) Work Motivation, Job Satisfaction and Organisational Commitment of Library Personnel in Academic and Research Libraries in Oyo State, Nigeria. Library Philosophy and Practice, 9, 1-16.

[12] Khwein, S.R. (2015) Organizational Trust and Its Effects to Verify the Commitment for Individual-Applied Research in Baghdad Company for Soda Water/Mixed Contribution. Vol. 35, Al-Mustansiyria University, Baghdad.

[13] Kazem, F.J. (2010) The Role of Organizational Identification in Enhancing Employees' Commitment. Al-Qadisiyah Journal for Administrative and Economic Sciences, 12, No. 3.

[14] Juladaydah, S.S.A. (2018) The Impact of Human Resource Management Strategies on the Performance of Employees in the Libyan Telecommunication Companies. Middle East University Amman. 